\title{
Assessing the effectiveness of global air-pollution treaties on $\mathrm{CO}_{2}$ emissions
}

\author{
A. Slechten ${ }^{1} \&$ V. Verardi ${ }^{2}$ \\ ${ }^{1}$ ECARES, Université libre de Bruxelles, Belgium \\ ${ }^{2}$ CRED (Center for Research in Economic Development), \\ University of Namur, Belgium
}

\begin{abstract}
This paper considers the effect of international air-pollution agreements ratified since 1970 on carbon dioxide emissions $\left(\mathrm{CO}_{2}\right)$, the main cause of anthropogenic climate change. The analysis is based on a panel dataset of 150 countries over the period 1970-2008. While the literature generally focuses on one particular agreement, we analyze the effect of the accumulation of agreements using a twoway (country, year) fixed effects regression model. We find th at the relationship between the number of ratifications and $\mathrm{C}_{2}$ emissions is statistically significant and linearly decreasing.

Keywords: air-pollution treaties, $\mathrm{CO}_{2}$ emissions, panel data.
\end{abstract}

\section{Introduction}

Due to the transboundary nature of the problem of climate change, international cooperation is essential. Hundreds of press articles have emphasized the failure of the global climate change agreements negotiated so far, in particular the so-called Kyoto Protocol, that was defined as a sinking ship by CNN (December 13, 2011). The economic literature is also very skeptical. Barrett [1], for example, states that "Kyoto does not provide the supporting incentives needed to effect a change in behavior over time". The objective of this paper is to revisit these pessimistic views since, even if we agree that the outcomes of specific treaties (such as the Kyoto Protocol) are very limited, we believe that there could be a virtuous accumulation effect of other non- $\mathrm{CO}_{2}$ specific treaties.

Indeed, a single source generally emits global pollutants as $\mathrm{CO}_{2}$ as well as more conventional air-pollutants as $\mathrm{SO}_{2}, \mathrm{NO}_{x}$ or VOC (e.g. see Barker [2] for 
the burning of fossil fuels). These conventional air-pollutants are responsible among others of acid rains and ambient air degradation. They are the targets of international treaties that follow the 1979 Convention on Long-Range Transboundary Air-Pollutant (LRTAP, hereafter). As they are very often realized with $\mathrm{CO}_{2}$ emissions, treaties flowing the 1979 LRTAP Convention may have an indirect impact on $\mathrm{CO}_{2}$ emissions. This impact can go in both direction. For example, switching from high to low sulfur coal to reduce $\mathrm{SO}_{2}$ emissions will imply carbon reductions as a by-product. On the other hand, scrubbers installed in power plants to neutralize $\mathrm{SO}_{2}$ use energy, and therefore, lead to more $\mathrm{CO}_{2}$ emissions.

To estimate the impact of these air-pollution treaties, we use a large crosscountry panel dataset over the period 1970-2008. We find that when treaties are considered individually, air-pollution agreements have a significant effect on $\mathrm{CO}_{2}$ emissions but we are unable to disentangle the effects of these agreements due to the large membership overlap between them. In contrast, when we study the effect of the accumulation of agreements, we eliminate the membership overlap problem. We find that each additional ratification of an air-pollution agreement is (in aggregate) associated with a reduction of $\mathrm{CO}_{2}$ emissions of about $4 \%$. This effect holds and is even reinforced when the number of ratifications is instrumented to cope with an eventual endogeneity of treaty adoption.

The approach used in this paper differs from the existing empirical literature on international environmental agreements. Indeed, almost all papers tend to concentrate exclusively on one particular pollutant agreement in a short time span (Bratberg et al. [3]; Finus and Tjøtta [4]; Aakvik and Tjøtta [5]) while we consider all international air-pollution treaties on a long time period. The structure of the paper is the following. In section 2, the data are presented with some stylized facts. In section 3, the different specifications used to estimate the model are presented. In section 4, we discuss the results. Section 5 concludes.

\section{Data and stylized facts}

\subsection{Data}

To study the effectiveness of air-pollution agreements in reducing carbon emissions, we use a large panel dataset of 150 countries over the period 19702008. The dependent variable is given by the (log of) level of $\mathrm{CO}_{2}$ emissions (in kilotons). Data on emissions come from the World Development Indicator (WDI) Dataset (World Bank, 2012 - http://data.worldbank.org/data-catalog/worlddevelopment-indicators).

To select the international agreements targeting air-pollutants released with $\mathrm{CO}_{2}$ emissions in most industrial processes (our variable of interest), we refer to the International Environmental Agreements Database Project (Version 2012.1, see http://iea.uoregon.edu/). A description of the database is made in Mitchell [6]. We consider ratification rather than signature as it is reasonable to assume that an agreement starts to matter once ratification through the parliament has occurred. 
This is in line with other empirical analysis (e.g. Bratberg et al. [3]). As a robustness check in the Results section, we also use a different definition of our variable of interest: an air-pollution agreement starts to matter after the treaty's official entry into force. The agreements of interest for this analysis belong to the Long-Range Transboundary Air-Pollution lineage, which consists of 7 treaties targeted to conventional air-pollutants, responsible for acid rains or degradations in ambient air quality.

This lineage started with the 1979 Convention on Long-Range Transboundary Air Pollution, which followed increasing concerns by policy-makers about the harmful effect of transboundary pollution caused by $\mathrm{SO}_{2}$ or $\mathrm{NO}_{x}$ emissions that can travel some hundreds of kilometers before deposition. This initial Convention was a declaration of good will and served as a basis for the 7 follow-up protocols.

To control for confounding effects, we use a set of control variables as suggested by the economic literature: economic activity measured by the Growth Domestic Product (GDP in constant 2000 US dollars) and the GDP growth rate, Total Population, Trade Openness measured as the sum of exports and imports of goods and services divided by GDP, the composition of the economic activity measured by the shares of agricultural and industrial productions in GDP and a Democracy Index (e.g. Friedl and Getzner [7]; van Vuuren and Riahi [8]; Li and Reuveny [9]; Shi [10]). Data come from the WDI Dataset, except the Democracy Index that comes from the Polity IV Database.

\subsection{Stylized facts}

Details on the air-pollution treaties used in this analysis can be found in the online appendix (https://sites.google.com/site/aurelieslechten/research). It shows that the number of ratifiers at the end of our sample period is roughly similar for all LRTAP agreements (i.e. it ranges from 19 to 29). The identity of the ratifiers is also much the same across them. At a country level, European countries are the ones that have ratified the largest number of agreements. The gap in the number of ratifications between the United States (US) and Europe has increased sharply since 1995. In contrast, China did not ratify any international air-pollution agreement so far. Since the first ratification of the Helsinki Protocol in 1985, the time span between two agreements is relatively short (generally less than 5 years).

Concerning $\mathrm{CO}_{2}$ emissions, data show that both Europe and the US have reduced their emissions between 1995 and 2008 while China's emissions have increased sharply during this period. From these first stylized facts, one might believe that it is because European countries have ratified several air-pollution treaties that they were able to reduce their $\mathrm{CO}_{2}$ emissions as a by-product.

\section{Specifications}

This section details the specifications used to test whether the first insights from the data can be confirmed. All the specifications are estimated using a standard panel two-way fixed effects estimator. To control for heteroskedasticity and within 
country serial correlation, standard errors are estimated using the Huber-White sandwich estimator, clustered at the country level.

\subsection{Agreement-specific model}

We first estimate an agreement-specific model in order to test for the effectiveness of each agreement individually (as it is usually done in the literature): for $k=$ $1, \ldots 7$

$$
\log \left(C O_{2}\right)_{i t}=\alpha_{i}+\delta_{t}+\beta_{k} \operatorname{rat}(k)_{i t-1}+\mathbf{Z}_{i t} \gamma+\varepsilon_{i t}
$$

where $\log \left(\mathrm{CO}_{2}\right)_{i t}$ is the $\log$ of $\mathrm{CO}_{2}$ emissions of country $i$ in year $t, \alpha_{i}$ is the country fixed effect, $\delta_{t}$ is the time fixed effect and $\mathbf{Z}_{i t}$ is the matrix containing all control variables for country $i$ in year $t$. Controlling for unobserved heterogeneity is needed to capture factors such as country specific technology, regulation, ideology and economic conditions such as the world business cycle. The variable of interest is $\operatorname{rat}(k)_{i t-1}$. It is coded as a dummy variable:

$$
\operatorname{rat}(k)_{i t-1}= \begin{cases}1 & \text { if country } i \text { has ratified agreement } k \text { at } t-1 \\ 0 & \text { otherwise }\end{cases}
$$

\subsection{Basic model}

Due to the large membership and timing overlap between the treaties used in this analysis (see Stylized Facts), it may be difficult to identify the effect of each agreement: we cannot be sure that the impact captured by the previous specification is really the impact of the treaty analyzed or the impact of a treaty ratified nearly at the same time by similar countries.

Moreover, we believe that it is the accumulation of agreements that has an effect on $\mathrm{CO}_{2}$ emissions. Indeed, the sources of anthropogenic greenhouse gas emissions are various, so a unique air-pollution agreement can not tackle all the aspects of the problem. By ratifying additional agreements, countries might enrich the initial agreement and control other sources of emissions. We thus estimate the following model, which will be our basic specification:

$$
\log \left(C \mathrm{O}_{2}\right)_{i t}=\alpha_{i}+\delta_{t}+\beta(\# A I R)_{i t-1}+Z_{i t} \gamma+\varepsilon_{i t}
$$

where $(\# A I R)_{i t-1}$, the variable of interest, is the number of air-pollution agreements ratified by country $i$ at time $t-1$ and is computed as follows: for $k=1, \ldots, 7$

$$
\# A I R_{i t}=\sum_{k=1}^{7} \operatorname{rat}(k)_{i t}
$$

We expect the coefficient estimated for the number of ratified air-pollution agreements to be negative and significantly different from zero. This would indeed imply that ratifying an additional air-pollution agreement is associated with a reduction of $\mathrm{CO}_{2}$ emissions in the ratifying country. 


\subsection{Non-linear model}

To tackle a possible non-linearity of the relationship between agreements ratification and $\mathrm{CO}_{2}$ emissions, we consider the following model:

$$
\log \left(C O_{2}\right)_{i t}=\alpha_{i}+\delta_{t}+\sum_{j=1}^{J} \beta_{j} I\left((\# A I R)_{i t-1}=j\right)+Z_{i t} \gamma+\varepsilon_{i t}
$$

where $I\left((\# A I R)_{i t-1}=j\right)$ is equal to 1 if country $i$ has ratified $j$ agreements at time $t-1$. Coefficients $\beta_{j}$ will then be the reduction of $\mathrm{CO}_{2}$ emissions when $j$ agreements have been ratified. As it will be shown in the results (see section 4), the non-linearity is rejected. Therefore, we keep the linear specification throughout the rest of the paper.

\subsection{IV-GMM model}

The results of the basic specification may be biased due to a possible reverse causality between ratification and $\mathrm{CO}_{2}$ emissions: it is precisely because they are not the biggest polluters that European countries participate in many agreements (as they do not pollute much, it is not very costly for them to ratify many treaties). To account for this, we instrument our variable of interest, $(\# A I R)_{i t}$ and estimate our basic model using an IV-GMM estimator for fixed effects models. Ratifying air-pollution agreements signals a preference for multilateral international policy initiative. Our idea is to use these preferences (that are not directly related to $\mathrm{CO}_{2}$ emissions) as instrument for our variable of interest in the basic specification.

As a proxy for these preferences, we use the number of ratified environmental agreements (a different kind of international policy initiatives) that do not address air-pollution (treaties concerning the conservation of species and fresh water resources) and a death penalty index. The argument behind the use of the death penalty index is the following: a country's decision regarding the death penalty and preferences for multilateralism can both be related to a country's conservatism. In the context of multilateral aid, Milner and Tingley [11] show that the preferences for multilateralism are explained by the ideology of individuals, i.e. in the US, Conservatives are typically much more opposed to sending multilateral aid. On the other hand, Neumayer [12] shows that the political orientation of the government in power (e.g. Conservative) is a significant determinant of the status of the death penalty. A more conservative (or traditional) and religious country will therefore be less prone to abolish the death penalty. This is why we believe that decisions regarding the status of the death penalty will be related to decisions concerning the ratification of international agreements through cultural values such as conservatism and tradition. Finally, to be a good instrument in the context of panel data, there must be sufficient heterogeneity among countries regarding the abolition of the death penalty and the index must also vary over time. This is the case as we reject the null hypothesis of no variation through time within a country 
(the F-statistic is $\mathrm{F}(38,5662)=88.69$, with a p-value of 0.00 ) and no variation between countries (the F-statistic is $F(149,5662)=109.43$, with a p-value of 0.00 ).

With these two instruments, our first-stage equation is given by:

$$
(\# A I R)_{i t}=\tilde{\alpha}_{i}+\tilde{\delta}_{t}+\psi I E A_{i t}+\phi D P_{i t}+Z_{i t} \theta+u_{i t}
$$

$I E A_{i t}$ is the number of environmental agreements ratified by country $i$ at time $t$ (Data come from the IEA Database) and $D P$ is the death penalty index. The status of the death penalty is constructed as follows (from Amnesty International): we measure the status of the death penalty on a five-point scale (0-4), from constitutionally authorization of the death penalty (0) to abolition of the death penalty for any offense in both peace and war periods (4).

Our identifying assumptions are that (1) these instruments do not affect the level of $\mathrm{CO}_{2}$ emissions directly, so that the instruments can be excluded from our second-stage regression, and (2) ratification of these environmental treaties and the decisions regarding the death penalty are not caused by the level of $\mathrm{CO}_{2}$ emissions.

\section{Results}

\subsection{Agreement-specific model}

Results for variable of interest (individual agreements) of the agreement-specific model are presented in Figure 1(a). Results for the control variables are very similar to those of models analyzed in the next section. It appears that all the LRTAP treaties have a significant negative impact on $\mathrm{CO}_{2}$ emissions. Furthermore, their effects are relatively similar. However, it is not clear which effect we capture, due to the substantial overlap in terms of membership and timing.

\subsection{Basic model}

Results for the three other specifications are presented in Table 1. In all specifications, the quality of the fit is rather good, since the within R-square is at least 0.65 .

Results for the basic specification are shown in columns 1 to 3 of Table 1 . This basic specification tests for the presence of an accumulation effect of air-pollution agreements. Column 1 and 2 report the results when we consider ratification as the point in time from which an agreement start to matter (for different sets of control) while column 3 reports results when a treaty's entry into force is considered. Ratification by one country of an additional air-pollution agreement is associated with a reduction by approximatively $4 \%$ of its $\mathrm{CO}_{2}$ emissions. This implies that if all countries ratify an additional air-pollution agreement, the world $\mathrm{CO}_{2}$ emissions will be reduced by $4 \%$.

Most control variables have the expected sign. A higher GDP level is associated with higher $\mathrm{CO}_{2}$ emissions. The GDP growth rate coefficient has a negative sign, indicating that energy efficiency improvements seem to offset increases in 
Table 1: Estimating the effect of the number of ratifications on $\mathrm{CO}_{2}$ emissions.

Dependent variable: $\log \left(\mathrm{CO}_{2}\right)$

\begin{tabular}{|c|c|c|c|c|c|}
\hline Variables & $\begin{array}{c}\text { Basic FE } \\
\text { (initial) }\end{array}$ & $\begin{array}{l}\text { Basic FE } \\
\text { (controls) }\end{array}$ & $\begin{array}{c}\text { Basic FE } \\
\text { (entry) }\end{array}$ & IV-GMM & $\begin{array}{l}\text { Non } \\
\text { linear }\end{array}$ \\
\hline$\# A I R(\mathrm{t}-1)$ & $\begin{array}{c}-0.059 * * * \\
(0.013)\end{array}$ & $\begin{array}{c}-0.040^{* * *} \\
(0.013)\end{array}$ & $\begin{array}{c}-0.039^{* * *} \\
(0.013)\end{array}$ & $\begin{array}{c}-0.090 * * \\
(0.040)\end{array}$ & $\begin{array}{c}\text { See } \\
\text { Fig. 1(b) }\end{array}$ \\
\hline $\log (\mathrm{GDP})(\mathrm{t})$ & $\begin{array}{c}0.948^{* * *} \\
(0.088)\end{array}$ & $\begin{array}{c}0.940 * * * \\
(0.107)\end{array}$ & $\begin{array}{c}0.940 * * * \\
(0.107)\end{array}$ & $\begin{array}{c}0.910 * * * \\
(0.113)\end{array}$ & $\begin{array}{c}0.940 * * * \\
(0.108)\end{array}$ \\
\hline $\log ($ Population $)(t)$ & $\begin{array}{c}0.681 * * * \\
(0.159)\end{array}$ & $\begin{array}{c}0.536 * * * \\
(0.189)\end{array}$ & $\begin{array}{c}0.552 * * * \\
(0.188)\end{array}$ & $\begin{array}{l}0.365^{*} \\
(0.209)\end{array}$ & $\begin{array}{c}0.506^{* * *} \\
(0.192)\end{array}$ \\
\hline $\log$ (Openess) (t) & & $\begin{array}{c}0.027 \\
(0.056)\end{array}$ & $\begin{array}{c}0.028 \\
(0.056)\end{array}$ & $\begin{array}{c}0.029 \\
(0.057)\end{array}$ & $\begin{array}{c}0.026 \\
(0.056)\end{array}$ \\
\hline $\begin{array}{l}\text { GDP Growth } \\
\text { Rate (t) }\end{array}$ & $\begin{array}{c}-0.585 * * * \\
(0.139)\end{array}$ & $\begin{array}{c}-0.707 * * * \\
(0.152)\end{array}$ & $\begin{array}{c}-0.703 * * * \\
(0.152)\end{array}$ & $\begin{array}{c}-0.752 * * * \\
(0.150)\end{array}$ & $\begin{array}{c}-0.702 * * * \\
(0.152)\end{array}$ \\
\hline $\begin{array}{l}\log \text { (Prop. } \\
\text { Agriculture) (t) }\end{array}$ & & $\begin{array}{c}0.105 \\
(0.086)\end{array}$ & $\begin{array}{c}0.106 \\
(0.086)\end{array}$ & $\begin{array}{c}0.082 \\
(0.113)\end{array}$ & $\begin{array}{c}0.101 \\
(0.093)\end{array}$ \\
\hline $\log$ (Prop. & & $0.318^{* * * *}$ & $\begin{array}{c}0.317 * * * \\
(0.091)\end{array}$ & $\begin{array}{c}0.306^{* * *} \\
(0.092)\end{array}$ & $\begin{array}{c}0.312^{* * * *} \\
(0.092)\end{array}$ \\
\hline $\begin{array}{l}\text { Industry) (t) } \\
\text { Democracy }\end{array}$ & & $\begin{array}{c}(0.091) \\
0.007 \\
(0.005)\end{array}$ & $\begin{array}{c}(0.091) \\
0.007 \\
(0.005)\end{array}$ & $\begin{array}{c}(0.092) \\
0.005 \\
(0.005)\end{array}$ & $\begin{array}{c}(0.092) \\
0.007 \\
(0.005)\end{array}$ \\
\hline Obs & 4,834 & 4,275 & 4,275 & 4,274 & 4,275 \\
\hline Within R-sq. & 0.658 & 0.663 & 0.662 & 0.658 & 0.663 \\
\hline Countries & 150 & 150 & 150 & 149 & 150 \\
\hline
\end{tabular}

Robust standard errors clustered by country in parentheses,

$* * * p<0.01, * * p<0.05, * p<0.1$.

Table 2: IV statistics.

\begin{tabular}{llc}
\hline Under-identification test & Kleibergen-Paap rk LM statistic & $\begin{array}{c}18.994 \\
\text { Chi-sq(3) p-value }\end{array}$ \\
& & 0.000 \\
\hline Weak identification test & Kleibergen-Paap rk Wald F statistic & 18.993 \\
Critical value at 5\%* & 5\% maximal IV relative bias & 13.91 \\
\hline \multirow{2}{*}{ Over-identification test } & Hansen J statistic & 2.637 \\
& Chi-sq(2) p-value & 0.2676 \\
\hline
\end{tabular}

*Note: Critical values for the Cragg-Donald Wald F statistic. 


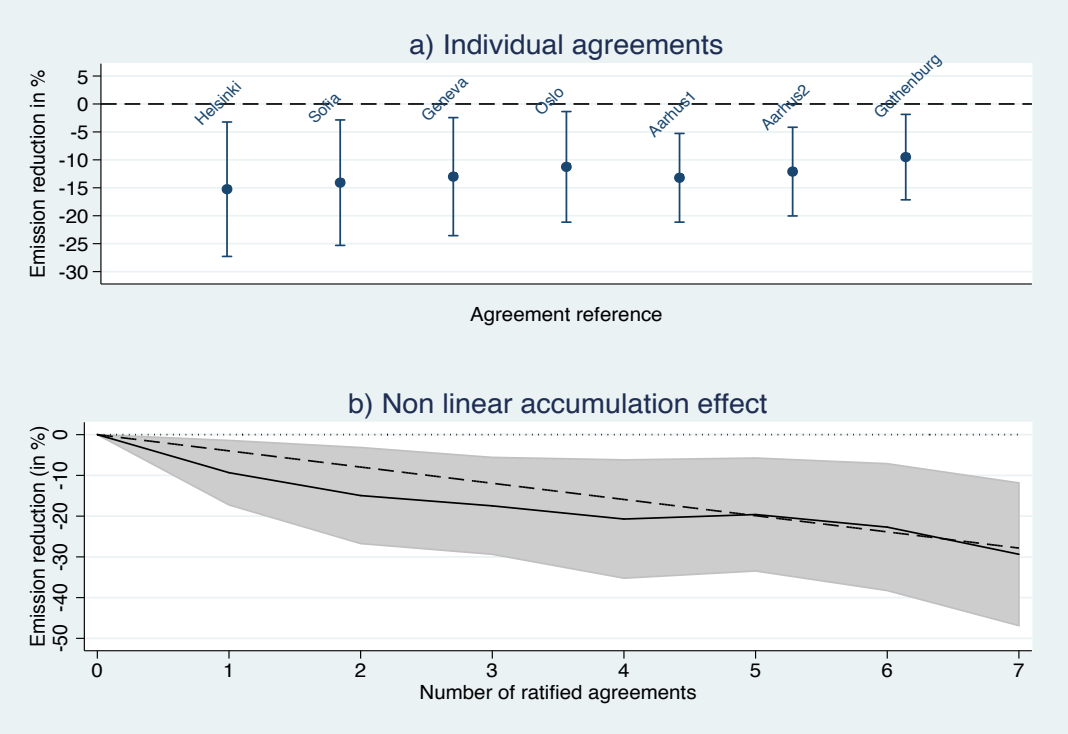

Figure 1: Results for agreement-specific and non-linear models.

energy consumption during periods of economic growth. The coefficients of trade openness and population are not significant. Both the shares of agricultural and industrial productions imply an increase of $\mathrm{CO}_{2}$ emissions, but only the industrial production has a significant impact.

\subsection{Non linear model}

The results for the non-linear model are presented in Table 1 (column 5) and in Figure 1(b). The solid line corresponds to the estimated coefficients of the number of ratified agreements (i.e. $\beta_{j}$ in the non-linear model). The grey area represents the confidence interval.

The relationship between $\mathrm{CO}_{2}$ emissions and ratification of air-pollution agreements seems to be linear. Indeed, the dashed line on Figure 1(b) corresponds to the linear relationship between ratification and $\mathrm{CO}_{2}$ emission reductions estimated by the basic specification, i.e. with a slope of $4 \%$ and this dashed line is completely included in the confidence interval of the estimated coefficients of the non-linear model.

\subsection{IV-GMM model}

The results for the IV-GMM estimators are presented in Table 1 (column 4) and the quality of the instruments is checked with tests defined in Table 2. Once 
we control for reverse causality, the effect of ratification remains and is even reinforced (reduction of about $9 \%$ of $\mathrm{CO}_{2}$ emissions).

Instruments are quite strong (see Table 2). Indeed, we are sure at $95 \%$ that the bias associated to the coefficient of interest is at most $5 \%$ of that of OLS (weak identification test). The joint null hypothesis of the over-identification test, i.e. that the instruments are valid instruments, is not rejected. From the underidentification test, we can conclude that the first-stage equation is identified, i.e. the excluded instruments ( $I E A$ and $D P$ ) are relevant (correlated with the endogenous regressor).

\section{Conclusion}

We show that there is an accumulation effect of the number of air-pollution agreements on the level of $\mathrm{CO}_{2}$ emissions. In aggregate, the air-pollution agreements ratified since 1970 have had a significant negative impact on $\mathrm{CO}_{2}$ emissions. We also deal with the problem of reverse causality by instrumenting the variable of interest (the number of ratified air-pollution agreements). We use exogenous instruments and show that the effect of ratification on emissions is reinforced.

This result indicates that the options used to reduce $\mathrm{SO}_{2}$ or $\mathrm{NO}_{x}$ emissions imply carbon reductions as a byproduct (e.g. fuel switching or use of low sulfur coal). An interesting question is why these LRTAP agreements seem to have been effective in reducing air-pollution, while a $\mathrm{CO}_{2}$-specific treaty as the Kyoto Protocol has been considered as poorly effective in the literature. We suggest two interpretations based on the nature of LRTAP treaties to explain their effectiveness. First, $\mathrm{SO}_{2}$ and $\mathrm{NO}_{x}$ are more local pollutants, compared to $\mathrm{CO}_{2}$. Intuitively, local agreements imply a higher commitment than more global agreements: politicians have a greater incentive to set more ambitious targets for local pollutants (and indirectly for $\mathrm{CO}_{2}$ as a by-product), because the effects of this pollution are more visible to the voters. Second, LRTAP treaties are more focused than the Kyoto Protocol, for example: each LRTAP treaty deals with only one air-pollutant (except the 1999 Gothenburg Protocol) while the Kyoto Protocol deals with different greenhouse gases. On the other hand, LRTAP agreements have not only clear targets but well identified means to meet these targets, whereas the Kyoto protocol has less clear means to achieve them. For example, the annexes of these agreements include a description of the measures available to reduce the pollutant covered by the treaty.

\section{References}

[1] Barrett, S., Global Climate Change and the Kyoto Protocol (Chapter 15). Environment and Statecraft: The Strategy of Environmental Treaty-making, ed. Oxford University Press: Oxford, pp. 359-398, 2003. 
[2] Barker, T., Ancillary benefits of greenhouse gas abatement: The effects of a UK carbon/energy tax on air pollution, Discussion Paper No. 4, Department of Applied Economics, University of Cambridge, UK, 1993.

[3] Bratberg, E., Tjøtta, S., Øines, T., Do voluntary international environmental agreements work?, Journal of Environmental Economics and Management, 50 (3), pp. 583-597, 2005.

[4] Finus, M., Tjøtta, S., The Oslo Agreement on sulfur reduction in Europe: the great leap forward?, Journal of Public Economics, 87 (9-10), pp. 2031-2048, 2003.

[5] Aakvik, A., Tjøtta, S., Do collective actions clear common air? The effect of international environmental protocols on sulphur emissions, European Journal of Political Economy, 27 (2), pp. 343-351, 2011.

[6] Mitchell, R.B., International environmental agreements: a survey of their features, formation, and effects, Annual Review of Environment and Resource, 28, pp. 429-461, 2003.

[7] Friedl, B., Getzner, M., Determinants of $\mathrm{CO}_{2}$ emissions in a small open economy, Ecological Economics 45 (1), pp. 133-148, 2003.

[8] van Vuuren, D. P., Riahi, K., Do recent emission trends imply higher emissions forever?, Climatic Change, 91 (3-4), pp. 237-248, 2008.

[9] Li, Q., Reuveny, R., Democracy and environmental degradation, International Studies Quarterly, 50 (1), pp. 935-956, 2006.

[10] Shi, A., The impact of population pressure in global carbon dioxide emissions, 1975-1996: evidence from pooled cross-country data, Ecological Economics, 44 (1), pp. 29-42, 2002.

[11] Milner, H., Tingley D., The choice for multilateralism: foreign aid and American foreign policy, Review of International Organizations, 8 (3), pp. 313-341, 2013.

[12] Neumayer, E., Death penalty: the political foundations of the global trend toward abolition. Human Rights Review, 9 (2), pp. 241-268, 2008. 